\title{
BMJ Open Usage of unscheduled hospital care by homeless individuals in Dublin, Ireland: a cross-sectional study
}

Clíona Ní Cheallaigh, ${ }^{1,2,3}$ Sarah Cullivan, ${ }^{1}$ Jess Sears, ${ }^{4}$ Ann Marie Lawlee, ${ }^{1}$ Joe Browne, ${ }^{1}$ Jennifer Kieran, ${ }^{1}$ Ricardo Segurado, ${ }^{5}$ Austin O'Carroll, ${ }^{6,7,8}$ Fiona O'Reilly, Donnacha Creagh, ${ }^{1,2}$ Colm Bergin, Rose Anne Kenny, ${ }^{1,2}$ Declan Byrne ${ }^{1,2}$

To cite: Ní Cheallaigh C, Cullivan S, Sears J, et al. Usage of unscheduled hospital care by homeless individuals in Dublin, Ireland: a crosssectional study. BMJ Open 2017;7:e016420. doi:10.1136/ bmjopen-2017-016420

- Prepublication history for this paper is available online. To view please visit the journal online (http://dx.doi.org/10. 1136/bmjopen-2017-016420).

Received 21 April 2017 Revised 26 August 2017 Accepted 11 September 2017

\section{(a) CrossMark}

${ }^{1}$ St James's Hospital, Dublin, Ireland

${ }^{2}$ Trinity College, Dublin, Ireland ${ }^{3}$ National SpR Academic Fellowship Programme, Dublin, Ireland

${ }^{4}$ Depaul Ireland, Dublin, Ireland ${ }^{5}$ UCD School of Public Health, Physiotherapy and Sports Science, Dublin, Ireland

${ }^{6}$ Partnership for Health Equity, Dublin, Ireland

${ }^{7}$ North Dublin City GP Training

Programme, Dublin, Ireland

${ }^{8}$ Safetynet Dublin, Dublin,

Ireland

Correspondence to Dr Clíona Ní Cheallaigh; nicheacm@tcd.ie, clionani@gmail.com

\section{ABSTRACT}

Objectives Homeless people lack a secure, stable place to live and experience higher rates of serious illness than the housed population. Studies, mainly from the USA, have reported increased use of unscheduled healthcare by homeless individuals. We sought to compare the use of unscheduled emergency department (ED) and inpatient care between housed and homeless hospital patients in a highincome European setting in Dublin, Ireland.

Setting A large university teaching hospital serving the south inner city in Dublin, Ireland. Patient data are collected on an electronic patient record within the hospital.

Participants We carried out an observational crosssectional study using data on all ED visits $(n=47174)$ and all unscheduled admissions under the general medical take $(n=7031)$ in 2015.

Primary and secondary outcome measures The address field of the hospital's electronic patient record was used to identify patients living in emergency accommodation or rough sleeping (hereafter referred to as homeless). Data on demographic details, length of stay and diagnoses were extracted.

Results In comparison with housed individuals in the hospital catchment area, homeless individuals had higher rates of ED attendance ( 0.16 attendances per person/annum vs 3.0 attendances per person/annum, respectively) and inpatient bed days ( 0.3 vs 4.4 bed days/person/annum). The rate of leaving ED before assessment was higher in homeless individuals ( $40 \%$ of ED attendances vs $15 \%$ of $\mathrm{ED}$ attendances in housed individuals). The mean age of homeless medical inpatients was 44.19 years $(95 \% \mathrm{Cl} 42.98$ to 45.40 ), whereas that of housed patients was 61.20 years (95\% Cl 60.72 to 61.68). Homeless patients were more likely to terminate an inpatient admission against medical advice $(15 \%$ of admissions vs $2 \%$ of admissions in homeless individuals).

Conclusion Homeless patients represent a significant proportion of ED attendees and medical inpatients. In contrast to housed patients, the bulk of usage of unscheduled care by homeless people occurs in individuals aged 25-65 years.

\section{INTRODUCTION}

Homeless people lack a secure, stable place to live. There are a variety of definitions of

\section{Strengths and limitations of this study}

- Use of large hospital-wide dataset including all emergency department presentations and medical admissions.

- Presentations to other hospitals not captured.

- Identification of homeless patients based on self-reported address at time of presentation to hospital as either no fixed abode or emergency accommodation, individuals giving an address of family or friends not identified as homeless.

- Absence of data on the duration and nature of homelessness.

homelessness $^{1}$ : the European Typology of Homelessness and Housing Exclusion defines a person as roofless or homeless if they have a identification deficit in at least two of the following: no dwelling, no legal title to a place for exclusive possession, and no private and safe space for social relations. ${ }^{2}$ This definition of homelessness includes those who are sleeping rough (ie, those sleeping in the open air); those living in emergency accommodation such as a hostel, night shelter or $\mathrm{B} \& \mathrm{~B}$ accommodation; those living with family and friends, or in a squat. Homelessness may be chronic (lasting $>1$ year), intermittent or short-term/crisis-related. ${ }^{3}$ In November 2015 , the Dublin Regional Homeless Executive reported 3615 adults in emergency accommodation and a minimum of 91 individuals sleeping rough in Dublin. ${ }^{4}$

Homelessness is associated with ill-health. Many homeless people have multiple simultaneous chronic conditions, termed multimorbidity. ${ }^{5}$ The simultaneous trimorbidity of physical ill-health, mental ill-health and drug or alcohol misuse is highly prevalent in homeless people. ${ }^{6}$ Diseases related to alcohol and/ or drug addiction including cirrhosis, infective endocarditis, abscesses, venous ulcers, 


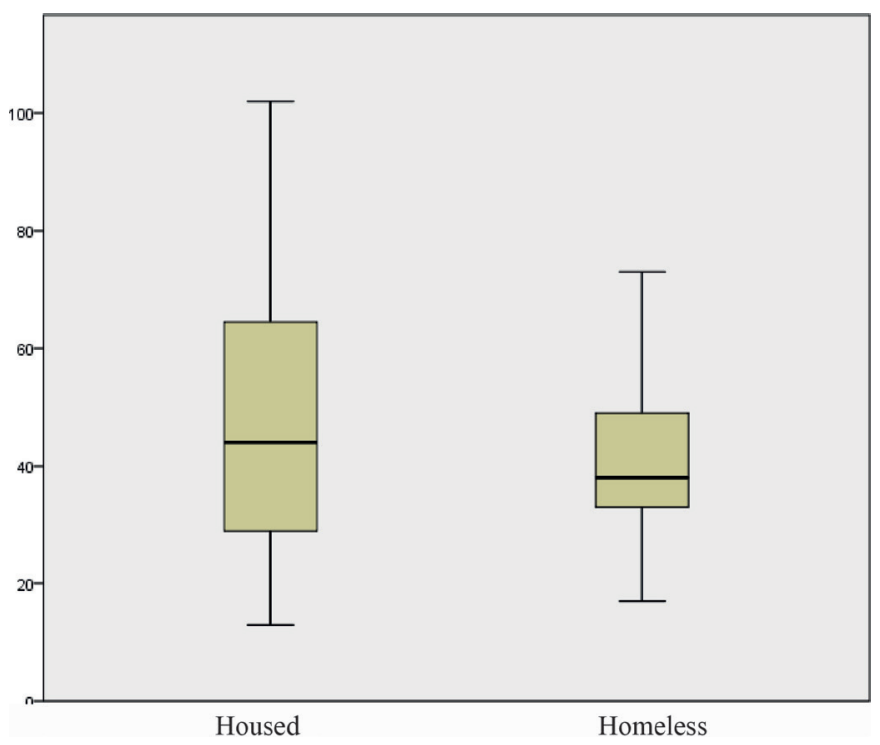

Figure 1 Age of housed and homeless ED attenders. ED, emergency department.

infection with hepatitis $\mathrm{C}$ and HIV are more prevalent in homeless than housed people. ${ }^{7}$ In addition, studies from the USA and Canada have reported earlier onset in homeless people of frailty and other geriatric syndromes usually seen in older adults. ${ }^{8-10}$

Homeless people have been reported to use relatively little primary care, ${ }^{11}$ and often use the emergency department (ED) as their initial point of contact with healthcare. Internationally, homeless people have been reported to attend ED three to five times more frequently than housed individuals. ${ }^{12-15}$ Rates of inpatient admissions of homeless persons have also been found to be higher ${ }^{14} 1617$ with longer length of stay (LOS) and increased readmission rates. ${ }^{17} 18$

We sought to compare the age profile and use of unscheduled ED and inpatient care between housed and homeless individuals in Dublin, Ireland.

\section{METHODS}

\section{Study setting}

We carried out an observational cross-sectional study using data on all ED visits and all unscheduled admissions under the general medical take (internal medicine) in St James's Hospital, Dublin, in 2015. St James's Hospital is a large university teaching hospital serving adults resident in the south inner city in Dublin, Ireland. Patient data are collected on an electronic patient record (EPR) within the hospital and is also collected in the national hospital in-patient enquiry (HIPE) system, a computerised health information system designed to capture demographic, administrative and clinical data on all inpatient discharges from publicly funded acute hospitals in Ireland. Diagnoses recorded on the HIPE system are determined by trained coders on examination of patient records.

\section{Data extraction}

All ED attendances and unscheduled inpatient stays between the 1 January and 31December 2015 (inclusive) were extracted from hospital databases. Individuals were identified by a unique identifier (medical record number). LOS and outcomes of ED attendances and inpatient admissions were extracted from the hospital patient record.

Patients admitted under any medical specialty participating in the general medical take (internal medicine acute admissions) rota or under infectious diseases were defined as medical inpatients. This did not include patients admitted under geriatrics, neurology, nephrology, oncology, haematology, psychiatry or any surgical specialty. Geriatrics, neurology, nephrology, oncology and haematology were excluded because they do not participate in the unselected internal medical take. Age was defined as the age of the patient on the date of discharge from hospital. Patients without recorded address were excluded.

\section{Operational definition of homelessness}

Homeless individuals were defined as those with recorded addresses of no fixed abode (NFA) or any emergency accommodation (homeless hostels). Addresses were extracted from the patient record. Addresses are obtained from patients by trained receptionists on registration in the ED and are checked at each admission. The names and/or street addresses of homeless hostels were obtained from the Dublin Regional Homeless Authority Case Management website. The address field in the patient record was manually screened to identify addresses corresponding to homeless hostels. In addition, any addresses with more than two patients presenting from the same address within the calendar year were scrutinised to identify potential homeless hostels.

To assess the sensitivity of identifying homeless patients based on the address field in the EPR, patients who were referred to the Social Work Department for advice on homelessness were checked against those identified as homeless using the previous method.

\section{Operational definition of housed and homeless population of catchment area}

The catchment population of the hospital was obtained from previous publications. ${ }^{19}$ The homeless population of Dublin was taken from data collected by the Dublin Regional Homeless Executive, ${ }^{20}$ and the proportion of those falling within the catchment area of the hospital was estimated by consensus by the authors and by the head of research in the Dublin Regional Homeless Executive.

\section{Data analysis}

Data were analysed using SPSS. Mann-Whitney tests were used to compare differences in age and LOS between housed and homeless patients. Chi-squared was used to compare categorical data between housed and homeless patients. Spearman's rank correlation coefficient was 


\begin{tabular}{lc} 
Table 1 & \multicolumn{1}{c}{ Demographics of ED attenders } \\
\hline Number of individuals & 31775 \\
Woman, $\mathrm{n}(\%)$ & $15157(47.7)$ \\
\hline Age, median (range) & $44(13-102)$ \\
\hline Age (woman), median (range) & $45(13-102)$ \\
Age (man) median (range) & $43(13-99)$ \\
\hline Age $<25$ & $3386(15.4 \%)$ \\
Age 25-44 & $7349(33.6 \%)$ \\
Age 45-64 & $5205(23.7 \%)$ \\
Age 65-74 & $4542(20.8 \%)$ \\
Age $>75$ & $1392(6.4 \%)$ \\
\hline
\end{tabular}

Age data are in years.

ED, emergency department.

used to assess the association between age and LOS in housed and homeless patients.

\section{RESULTS}

The catchment population of St James's Hospital, Dublin is reported as 270000 . The homeless population sleeping rough or in emergency accommodation (hereafter referred to as homeless) of the catchment area was estimated as 1000 individuals, resulting in a prevalence of homelessness of $0.4 \%$ of the population of the catchment area.

Two-hundred and fifty address fields (including NFA and numerous homeless hostels as well as multiple spelling variants of the homeless hostels) were identified as homeless addresses and individuals giving these addresses as their current address were defined as homeless.

Hundred homeless patients were identified from referrals to hospital social workers for advice on homelessness. Seventy-two per cent of these had an address on their electronic patient record that had been identified as homeless.

Five ED attendances and 12 inpatient admissions had no address recorded.

\section{ED attendances}

The demographics of all ED attenders are described in table 1 .
Table 3 Outcomes of ED attendances

\begin{tabular}{llll}
\hline & $\begin{array}{l}\text { Housed } \\
(\mathbf{n}=44208)\end{array}$ & $\begin{array}{l}\text { Homeless } \\
(\mathbf{n}=2966)\end{array}$ & P value \\
\hline $\begin{array}{l}\text { Left before } \\
\text { seen/against } \\
\text { medical }\end{array}$ & $6870(15.5 \%)$ & $1207(40.7 \%)$ & $<0.05$ \\
advice & & & \\
Assessed & $37234(84.5 \%)$ & $1759(59.3 \%)$ & $<0.05$ \\
Deceased & $111(0.3 \%)$ & $1(0.1 \%)$ & $<0.05$ \\
Discharged & $\begin{array}{l}24374(65 \% \\
\text { of those } \\
\text { assessed) }\end{array}$ & $\begin{array}{l}1221(69 \% \text { of } \\
\text { those assessed) }\end{array}$ & $<0.05$ \\
& $\begin{array}{l}12749(35 \% \\
\text { of those } \\
\text { assessed) }\end{array}$ & $\begin{array}{l}537(31 \% \text { of } \\
\text { those assessed) }\end{array}$ & $<0.05$ \\
\hline
\end{tabular}

ED, emergency department.

Homeless individuals accounted for a disproportionally high number of ED attendances per proportion of the catchment population. Out of an estimated 1000 homeless adults in the catchment area, 909 (91\%) homeless adults presented to the ED over this time period compared with 30865 (11.4\%) of 270000 housed individuals in the catchment area. The rates of attendance per year were increased in homeless individuals and they accounted for increasing proportions of attenders with $>4$ /year or $>12$ / year attendances to the ED. Homeless ED attenders were predominantly males (table 2 ).

\section{Homeless ED attenders are younger than their housed counterparts}

The mean age of homeless ED attendees was 39 years (17-76) (95\% CI 37.2 to 40.8), whereas that of housed ED attendees was 45 years (16-102) (95\% CI 42.1 to 47.9$)$ (figure 1). The difference in distribution of age was statistically significant (Mann-Whitney, $\mathrm{P}=0.000$ ).

Homeless ED attenders were much more likely to leave the ED without being assessed or against medical advice (table 3). Rates of admission to the hospital in those who remained for assessment and management were similar between housed and homeless.

Patient presenting complaints were recorded at triage. These were then ranked in order of frequency in housed

Table 2 Demographics of housed and homeless ED attenders

\begin{tabular}{llll}
\hline & Housed & Homeless & P value \\
\hline ED attendances (\% of total attendances) & $44208(93.7 \%)$ & $2966(6.3 \%)$ & $<0.5$ \\
Individuals & 30865 & 1909 & $<0.5$ \\
Woman & $14969(48.5 \%)$ & $196)$ & $<0.5$ \\
ED attendances per capita of catchment population & $0.16 /$ person/annum & $3.0 /$ person/annum \\
$(95 \% \mathrm{Cl})$ & & & $57(9.3 \%)$ \\
Individuals with $\geq 4$ presentations per year & $592(90.7 \%)$ & $34(41 \%)$ & $<0.5$ \\
\hline Individuals with $\geq 12$ presentations per year & $48(59 \%)$ & $<0.5$ \\
\hline
\end{tabular}

ED, emergency department. 


\begin{tabular}{|c|c|c|}
\hline & Housed & Homeless \\
\hline 1 & $\begin{array}{l}\text { Limb problems }(8464, \\
19.1 \%)\end{array}$ & $\begin{array}{l}\text { Limb problems (383, } \\
12.9 \%)\end{array}$ \\
\hline 2 & $\begin{array}{l}\text { Abdominal pain }(4250 \text {, } \\
9.6 \%)\end{array}$ & $\begin{array}{l}\text { Overdose and poisoning } \\
(223,7.6 \%)\end{array}$ \\
\hline 3 & Chest pain $(3315,7.5 \%)$ & $\begin{array}{l}\text { Apparently drunk (196, } \\
6.6 \%)\end{array}$ \\
\hline 4 & Unwell adult $(2818,6.4 \%)$ & Unwell adult $(184,6.2 \%)$ \\
\hline 5 & $\begin{array}{l}\text { Shortness of breath } \\
(2655,6 \%)\end{array}$ & Head injury $(165,5.6 \%)$ \\
\hline 6 & Head injury $(1843,4.2 \%)$ & Mental illness (143, 4.8\%) \\
\hline 7 & Back pain $(1503,3.4 \%)$ & $\begin{array}{l}\text { Collapsed adult ( } 133 \text {, } \\
4.5 \%)\end{array}$ \\
\hline 8 & $\begin{array}{l}\text { Collapsed adult (1396, } \\
3.2 \%)\end{array}$ & $\begin{array}{l}\text { Abdominal pain (112, } \\
3.8 \%)\end{array}$ \\
\hline 9 & Headache $(1199,2.7 \%)$ & $\begin{array}{l}\text { Shortness of breath ( } 86 \text {, } \\
2.9 \%)\end{array}$ \\
\hline 10 & $\begin{array}{l}\text { Facial problems ( } 870, \\
2.0 \%)\end{array}$ & Chest pain $(85,2.9 \%)$ \\
\hline Other & 15782 (35.7\%) & $1257(42.4 \%)$ \\
\hline
\end{tabular}

ED, emergency department.

and homeless presenters (table 4). Presentations related to drug and alcohol use and mental health were more common in homeless ED attenders.

\section{Acute medical admissions}

A total of 5104 individuals had unscheduled general medical admissions in 2015 (table 5). Seventy-five per cent of admissions were in individuals aged $>45$ years. Homeless individuals demonstrated $\mathrm{a}>10$-fold increase in usage of unscheduled general medical inpatient bed days per capita of the catchment area compared with housed individuals (table 6). In contrast to housed medical inpatients, the majority of homeless medical inpatients were men.

Table 5 Demographics of unscheduled medical admissions N

\begin{tabular}{lc}
\hline Individuals & 5104 \\
Woman & $2551(50 \%)$ \\
\hline Age, median (range) & $62(15-102)$ \\
\hline Age (woman), median (range) & $65(16-102)$ \\
\hline Age (man), median (range) & $60(15-99)$ \\
\hline Age $<25$ & $282(4 \%)$ \\
\hline Age 25-44 & $1507(21.5 \%)$ \\
\hline Age 45-64 & $1944(27.7 \%)$ \\
\hline Age 65-84 & $2444(34.8 \%)$ \\
\hline Age $>85$ & $805(11.5 \%)$ \\
\hline
\end{tabular}

Age data are in years.
The mean age of homeless medical inpatients was 44.19 years (95\% CI 42.98 to 45.40 ), whereas that of housed medical inpatients was 61.20 years (95\% CI 60.72 to 61.68) (figure 2). The distribution of age was significantly different between the two groups ( $\mathrm{P}=0.000$, MannWhitney) (figure 3).

Bed days in patients aged $\leq 64$ years accounted for $33.8 \%$ (27 274/80 633) of bed days generated by all housed medical admissions, versus $88.3 \%$ (3689/4176) of bed days generated by all homeless medical admissions. This difference was statistically significant $(\mathrm{P}=0.000$, $\left.\mathrm{X}^{2}\right)$. Bed days in patients aged $\leq 44$ years accounted for $10.8 \%(8734 / 80633)$ of bed days generated by all housed medical admissions, versus $49.1 \%(2050 / 4176)$ of bed days generated by all homeless medical admissions. This difference was statistically significant $\left(\mathrm{P}=0.000, \mathrm{X}^{2}\right)$ (figure 3).

Use of unscheduled healthcare is age-related in housed, but not homeless people

Increasing age was strongly correlated with LOS in housed medical inpatients (Spearman correlation 0.257 $(0.233-0.292, \mathrm{P}<0.005)$, whereas this was not the case in homeless medical inpatient (Spearman correlation $-0.034(-0.222$ to $0.155, \mathrm{P}=0.12)$ ).

The 10 most frequent primary diagnoses for housed and homeless medical inpatients were determined (table 7). Acute respiratory diagnoses were frequent in both populations. Diagnoses associated with injecting drug use (abscesses and venous thromboembolic disease) and hepatitis $\mathrm{C}$ and/or alcohol use (hepatic failure and haematemesis) were more common in homeless inpatients. Cardiovascular disease (congestive heart failure and atrial fibrillation) were less common in homeless inpatients.

A higher proportion of homeless inpatients self-discharged against medical advice (table 8 ).

\section{DISCUSSION}

Homelessness is a state of extreme socioeconomic deprivation, and is associated with increased morbidity and increased use of unscheduled hospital care (ED visits and admissions). We found that, in Dublin, homeless individuals have a 20-fold increased use of ED and over 10-fold increased use of unscheduled medical inpatient bed than housed individuals. These findings are similar, although the relative increase is higher in Ireland, to those reported from the USA, Canada and the UK. ${ }^{81321-26}$

It is important to note a number of key demographic differences between homeless individuals in the USA and those in high-income European countries such as Ireland. Homeless populations in the USA include a high proportion of veterans and of ethnic minorities and those in Australia and Canada include a high proportion of individuals reporting themselves as Aboriginal/ First Nation. ${ }^{5}$ Homeless people in Dublin are predominantly white Irish, with $4 \%$ reporting themselves as Irish 
Table 6 Characteristics of housed and homeless unscheduled medical admissions

\begin{tabular}{llll}
\hline Medical admissions & Housed & Homeless \\
\hline Inpatient admissions & $6572(93.4 \%)$ & $459(6.5 \%)$ \\
\hline Individuals & 4853 & 261 \\
\hline Bed days & $80629(93.5 \%)$ & $4435(6.5 \%)$ \\
\hline Bed days per capita of catchment population & 0.3 bed days/person/annum & 4.4 bed days/person/annum \\
ICU bed days per capita of catchment & 6573 & $443(6.3 \%)$ \\
population (days/person/annum) & 0.03 bed & 0.4 bed \\
Mean LOS (range) (95\% Cl) & $12.2(0-726)(11.5$ to 12.96) & $9.41(0-369)(7.2$ to 11.6$)$ \\
Woman & $3306(51.3 \%)$ & $103(23.3 \%)$ & $<0.05$ \\
\hline Mean admissions & $1.87(1-11)(1.84-1.91)$ & $2.79(2.62-2.96)$
\end{tabular}

ICU, intensive care unit; LOS, length of stay.

Traveller. ${ }^{6}$ Very few Irish people are combat veterans. Eighty per cent of adults in emergency accommodation or rough sleeping in Dublin in January 2016 were $\leq 44$ years old, ${ }^{40}$ this contrasts with the ageing homeless population reported in the USA. ${ }^{27}$ In Dublin, homelessness is strongly associated with drug use: up to $70 \%$ of homeless individuals report having used illegal drugs with over half reporting injecting drugs. ${ }^{6}$ Free primary and secondary healthcare is available to those in the lowest one-third income bracket in Ireland.

In our study, homeless patients were much more likely to leave the ED without being seen ( $41 \%$ vs $16 \%$ in housed patients). Patients who leave the ED without being seen have been reported to represent the failure of an emergency care delivery system to meet its goals. ${ }^{28}$ These rates are similar to those reported by Svoboda in Toronto ${ }^{29}$ and higher than those reported from London. ${ }^{30}$ Anecdotally, some of the homeless individuals who leave without being seen may have simply been seeking shelter for the night in the ED waiting room, with others requiring medical attention leaving due to withdrawal from alcohol and/

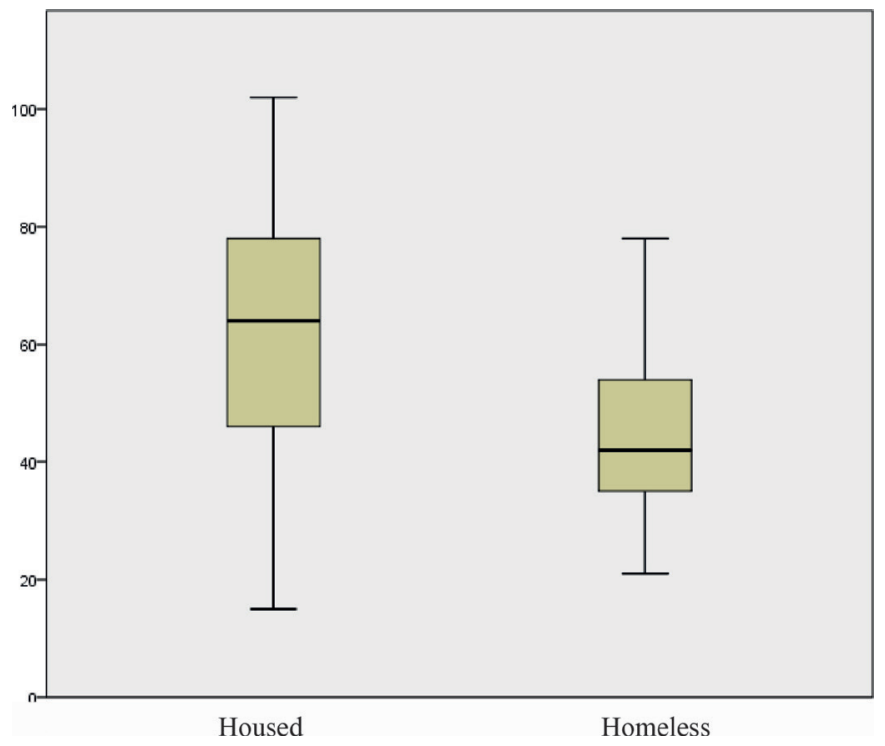

Figure 2 Age of unscheduled medical admissions. or opiates and attention deficit hyperactivity disorder-related difficulties with waiting. Homeless medical inpatients were also much more likely to self-discharge against medical advice.

Homeless individuals accounted for a grossly disproportionate amount of inpatient bed days relative to their proportion of the catchment population. Cardiovascular presentations (congestive heart failure, atrial fibrillation and chest pain) were less common in homeless than in housed patients, whereas diseases related to alcohol and drug use (abscesses, hepatic failure and haematemesis) were more common in homeless patients. Seizures were also more common in homeless patients, which may result from the increased rate of traumatic brain injury and substance use in this population. Both groups presented frequently with syncope, pneumonia and exacerbation of chronic obstructive pulmonary disease/ asthma. These presentations are common in elderly

\section{Bed days by age group}

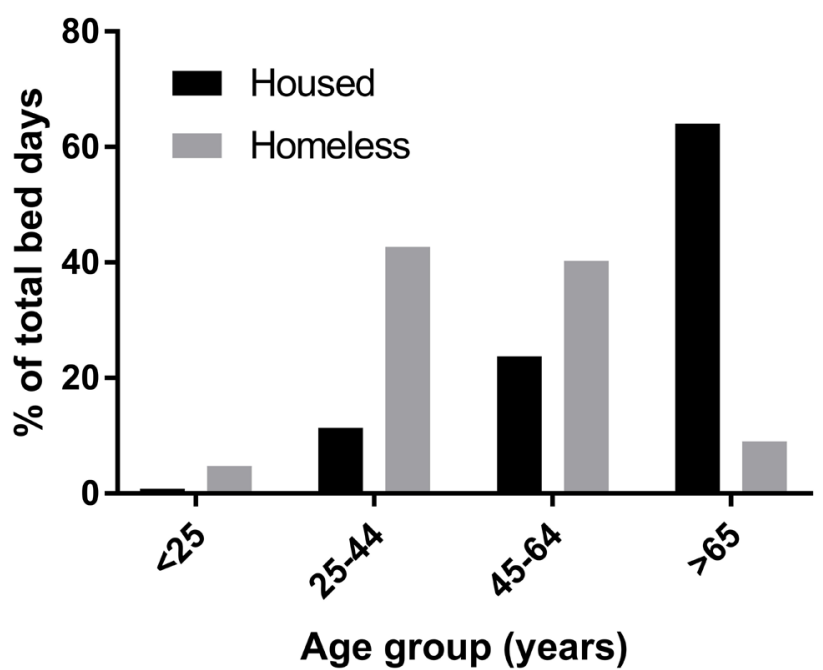

Figure 3 Bed days by age group. 


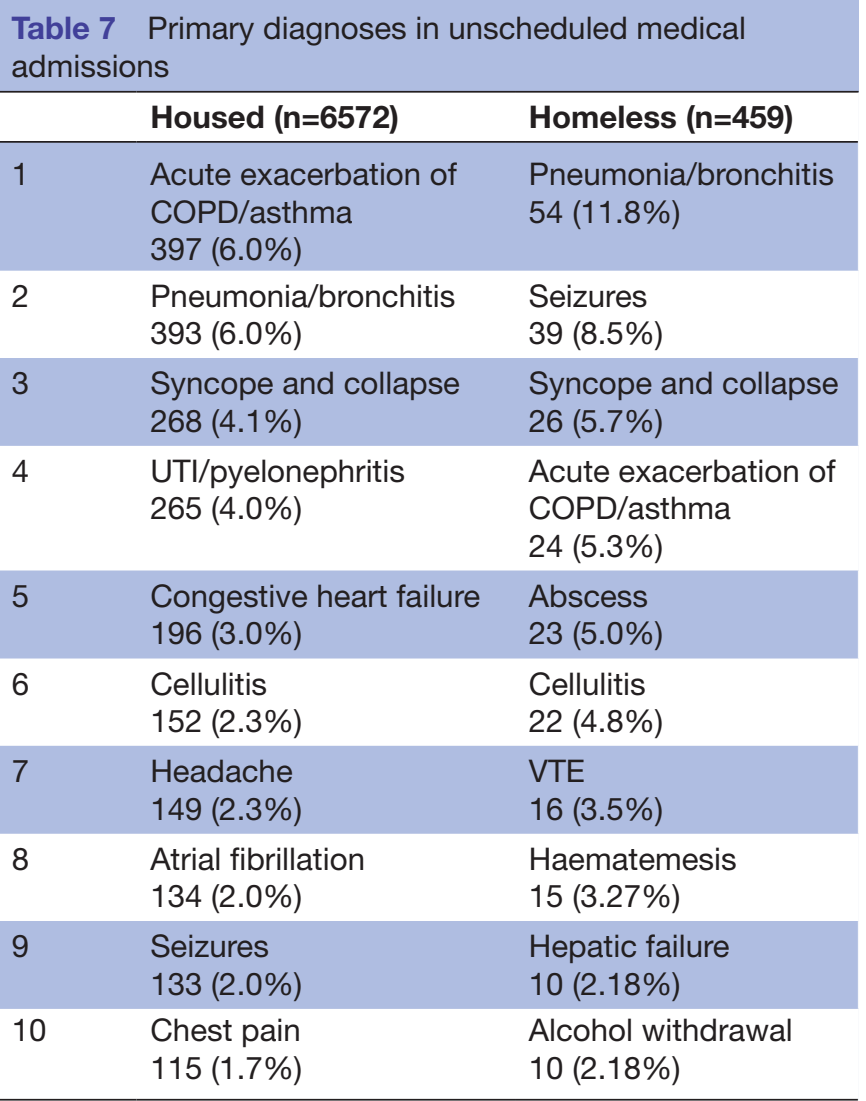

COPD, chronic obstructive pulmonary disease; UTI, urinary tract infection; VTE, venous thromboembolism.

housed populations, but are seen in homeless patients at a significantly younger age.

We demonstrate a striking difference in the age profile of homeless patients compared with housed patients. The median age of homeless medical inpatients was 20 years younger than that of housed patients. Most bed days generated by homeless patients were in patients $<65$ year of age, which contrasted with the housed population. Of note, we excluded unscheduled and elective admissions to the Geriatric service, which consist solely of housed individuals $>70$ years of age. Work by Kushel $e t a l^{8}$ on homeless veterans in the USA also reported a younger median age in homeless hospital patients with a 5-16year difference in median age between homeless and housed veterans presenting with medical conditions. Earlier mortality in homeless people may account for their relative under-representation in older inpatients.

Limitations of this study include that presentations to other hospitals were not captured, and that diagnoses were captured by non-clinician coders. An additional limitation of the study was that identification of homeless patients was based on the address recorded on the patient electronic record, with an estimated under-reporting rate of $30 \%$ and an inability to identify those who gave the address of a family member or friend. Estimates of the proportion of the homeless population of Dublin within the catchment area of the hospital are crude, and there is a significant degree of mobility of homeless people
Table 8 Outcome of admission

\begin{tabular}{lll}
\hline & Housed & Homeless \\
\hline $\begin{array}{l}\text { All unscheduled medical } \\
\text { admissions }\end{array}$ & 6572 & 459 \\
$\begin{array}{l}\text { Self-discharge } \\
\text { Deceased }\end{array}$ & $125(1.9 \%)$ & $67(14.6 \%)$ \\
$\begin{array}{l}\text { Discharged to home/ } \\
\text { homelessness }\end{array}$ & $151(2.3 \%)$ & $6(1.3 \%)$ \\
$\begin{array}{l}\text { Discharge to long-term care } \\
\text { Dis }\end{array}$ & $138(2.1 \%)$ & $0(0 \%)$ \\
\hline
\end{tabular}

within the city. However, the differences in usage of acute unscheduled care are so dramatic that even an underestimation of the homeless population by $100 \%$ in our study would result in a homeless population in the catchment area of only 2000 individuals, and the dramatic increase in use of unscheduled healthcare in homeless individuals compared with housed individuals would remain. Strengths of the study include the large number of patients included and the ability to focus analysis on medical inpatient admissions (thereby excluding psychiatric inpatient admissions).

\section{CONCLUSION}

Homelessness is associated with ill-health and dramatic decreases in life expectancy. In this study, we demonstrate that homelessness is also associated with a dramatic increase in the per capita use of costly unscheduled acute healthcare. A failure to address the structural causes of homelessness results in increased costs to society through increased use of healthcare, in addition to social care and opportunity costs. In contrast to housed patients, the bulk of usage of unscheduled care by homeless people occurs in individuals aged $25-65$ years. Earlier mortality in homeless people may account for their relative under-representation in older inpatients. Primary and ambulatory care for homeless people, if aiming to prevent costly inpatient admissions, will need to cater a significantly younger population than services for housed individuals.

Contributors CNC: literature search, figures, study design, data collection, data analysis, data interpretation and writing of manuscript. SC and DC: data collection. $\mathrm{JB}, \mathrm{JK}, \mathrm{CB}, \mathrm{RAK}$ and DB: editing of manuscript. FOR and AOC: literature search, data collection and editing of manuscript. RS: statistical advice.

Funding This work was supported by the Health Research Board and Health Services Executive under the grant NSAFP/2009/2.

Competing interests All authors have completed the Unified Competing Interest form and declare: support from the Health Research Board, Ireland (HRB) and the Health Services Executive, Ireland (HSE) for the submitted work; no financial relationships with any organisations that might have an interest in the submitted work in the previous 3 years, no other relationships or activities that could appear to have influenced the submitted work.

Ethics approval The study was approved by the Joint Research Ethics Committee of St James's Hospital and the Adelaide and Meath Hospital.

Provenance and peer review Not commissioned; externally peer reviewed.

Data sharing statement Extra data can be accessed via the Dryad data repository at http://datadryad.org/ with the doi:10.5061/dryad.0k8c4 
Open Access This is an Open Access article distributed in accordance with the Creative Commons Attribution Non Commercial (CC BY-NC 4.0) license, which permits others to distribute, remix, adapt, build upon this work non-commercially, and license their derivative works on different terms, provided the original work is properly cited and the use is non-commercial. See: http://creativecommons.org/ licenses/by-nc/4.0/

(c) Article author(s) (or their employer(s) unless otherwise stated in the text of the article) 2017. All rights reserved. No commercial use is permitted unless otherwise expressly granted.

\section{REFERENCES}

1. Fazel S, Geddes JR, Kushel M. The health of homeless people in high-income countries: descriptive epidemiology, health consequences, and clinical and policy recommendations. Lancet 2014; 384:1529-40.

2. FEANTSA. "On the Way Home?" FEANTSA Monitoring Report on Homelessness and Homelessness Policies in Europe. 2012.

3. Kuhn R, Culhane DP. Applying cluster analysis to test a typology of homelessness by pattern of shelter utilization: results from the analysis of administrative data. Am J Community Psychol 1998;26:207-32.

4. Dublin regional homeless executive, 2015.

5. Brett T, Arnold-Reed DE, Troeung L, et al. Multimorbidity in a marginalised, street-health Australian population: a retrospective cohort study. BMJ Open 2014;4:e005461.

6. O'Reilly F, Barror S, O'Carroll A. Homelessness: an unhealthy state: Partnership for health equity, 2015.

7. Beijer $U$, Wolf $A$, Fazel S. Prevalence of tuberculosis, hepatitis $C$ virus, and HIV in homeless people: a systematic review and metaanalysis. Lancet Infect Dis 2012;12:859-70.

8. Adams J, Rosenheck R, Gee L, et al. Hospitalized younger: a comparison of a national sample of homeless and housed inpatient veterans. J Health Care Poor Underserved 2007;18:173-84.

9. Gelberg L, Linn LS, Mayer-Oakes SA. Differences in health status between older and younger homeless adults. J Am Geriatr Soc 1990;38:1220-9

10. Brown RT, Kiely DK, Bharel M, et al. Geriatric syndromes in older homeless adults. J Gen Intern Med 2012;27:16-22.

11. O'Carroll A, O'Reilly F. Health of the homeless in Dublin: has anything changed in the context of Ireland's economic boom? Eur J Public Health 2008;18:448-53

12. Padgett DK, Struening EL, Andrews $\mathrm{H}$, et al. Predictors of emergency room use by homeless adults in New York City: the influence of predisposing, enabling and need factors. Soc Sci Med $1995 ; 41: 547-56$
13. Padgett $\mathrm{D}$, Struening EL, Andrews $\mathrm{H}$. Factors affecting the use of medical, mental health, alcohol, and drug treatment services by homeless adults. Med Care 1990;28:805-21.

14. Kushel MB, Vittinghoff E, Haas JS. Factors associated with the health care utilization of homeless persons. JAMA 2001;285:200-6.

15. Victor CR, Connelly J, Roderick P, et al. Use of hospital services by homeless families in an inner London health district. BMJ 1989;299:725-7.

16. Wenzel SL, Bakhtiar L, Caskey NH, et al. Homeless veterans' utilization of medical, psychiatric, and substance abuse services. Med Care 1995;33:1132-44.

17. Martell JV, Seitz RS, Harada JK, et al. Hospitalization in an urban homeless population: the Honolulu Urban Homeless Project. Ann Intern Med 1992;116:299-303.

18. Brown RT, Kimes RV, Guzman D, et al. Health care access and utilization in older versus younger homeless adults. $J$ Health Care Poor Underserved 2010;21:1060-70.

19. Cournane S, Byrne D, Conway R, et al. Social deprivation and hospital admission rates, length of stay and readmissions in emergency medical admissions. Eur J Intern Med 2015;26:766-71.

20. Dublin regional homeless executive. 2016. Homelessness Report.

21. Baggett TP, Jenkins DM. Homelessness and health: key themes from three decades of research. Poverty and health: a crisis among America's most vulunerable Santa Barbara: Praeger 2013:105-42.

22. Bharel M, Lin WC, Zhang J, et al. Health care utilization patterns of homeless individuals in Boston: preparing for Medicaid expansion under the Affordable Care Act. Am J Public Health 2013;103 Suppl 2(S2):S311-S317.

23. Black ME, Scheuer MA, Victor $C$, et al. Utilisation by homeless people of acute hospital services in London. BMJ 1991;303:958-61.

24. Breakey WR, Fischer PJ, Kramer M, et al. Health and mental health problems of homeless men and women in Baltimore. JAMA 1989;262:1352-7.

25. Wagner J, Diehl K, Mutsch L, et al. Health status and utilisation of the healthcare system by homeless and non-homeless people in Vienna. Health Soc Care Community 2014;22:300-7.

26. Robertson MJ, Cousineau MR. Health status and access to health services among the urban homeless. Am J Public Health 1986;76:561-3.

27. Culhane DP, Metraux S, Byrne T, et al. The Age Structure of Contemporary Homelessness: Evidence and Implications For Public Policy. Analyses of Social Issues and Public Policy 2013;13:228-44.

28. Hsia RY, Asch SM, Weiss RE, et al. Hospital determinants of emergency department left without being seen rates. Ann Emerg Med 2011:58:24-32.

29. Svoboda T. Difficult behaviors in the emergency department: a cohort study of housed, homeless and alcohol dependent individuals. PLOS One 2014;10:e0124528.

30. Brown AJ, Goodacre SW, Cross S. Do emergency department attendances by homeless people increase in cold weather? Emerg Med J 2010;27:526-9. 